\title{
8
}
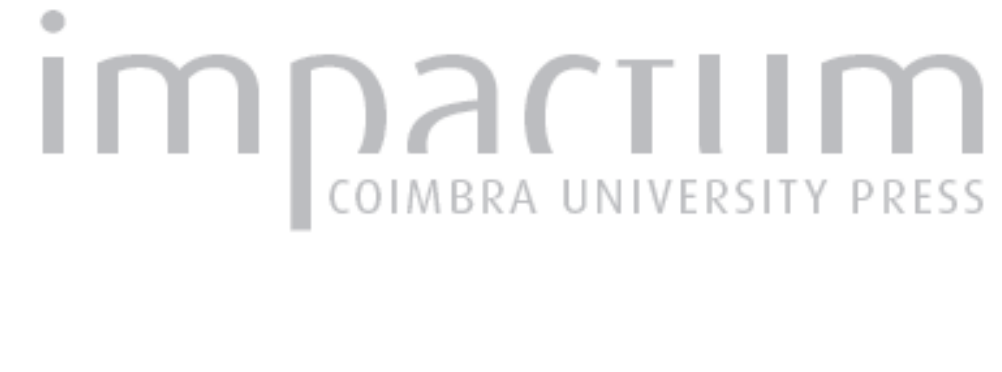

\section{A política do alargamento da União Europeia: génese, natureza e evolução}

\author{
Autor(es): $\quad$ Cunha, Alice
}

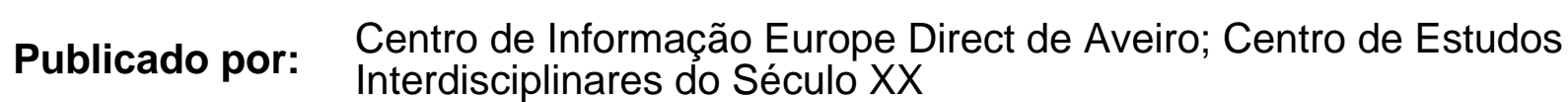

URL

persistente:

URI:http://hdl.handle.net/10316.2/33989

DOI:

DOI:http://dx.doi.org/10.14195/1647-6336_11_18

Accessed : $\quad$ 26-Apr-2023 10:07:38

A navegação consulta e descarregamento dos títulos inseridos nas Bibliotecas Digitais UC Digitalis, UC Pombalina e UC Impactum, pressupõem a aceitação plena e sem reservas dos Termos e Condições de Uso destas Bibliotecas Digitais, disponíveis em https://digitalis.uc.pt/pt-pt/termos.

Conforme exposto nos referidos Termos e Condições de Uso, o descarregamento de títulos de acesso restrito requer uma licença válida de autorização devendo o utilizador aceder ao(s) documento(s) a partir de um endereço de IP da instituição detentora da supramencionada licença.

Ao utilizador é apenas permitido o descarregamento para uso pessoal, pelo que o emprego do(s) título(s) descarregado(s) para outro fim, designadamente comercial, carece de autorização do respetivo autor ou editor da obra.

Na medida em que todas as obras da UC Digitalis se encontram protegidas pelo Código do Direito de Autor e Direitos Conexos e demais legislação aplicável, toda a cópia, parcial ou total, deste documento, nos casos em que é legalmente admitida, deverá conter ou fazer-se acompanhar por este aviso.

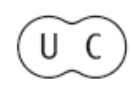


DEBATER

A EUROPA

jul-dez 2014

QUE EUROPA(S)?

CONTEXTOS E DESAFIOS 


\title{
A política do alargamento da União Europeia: génese, natureza e evolução
}

\author{
Alice Cunha \\ Doutora em História Contemporânea \\ Investigadora Integrada IHC-UNL \\ Investigadora de Pós-doutoramento FCT / IHC-UNL \\ E-mail: alice_mpbc@portugalmail.pt
}

\section{Resumo}

Nos anos 90, a questão do alargamento, primeiro dos países nórdicos e depois dos de leste, dominou a agenda da União Europeia (UE). Enquanto ainda se negociava a adesão da Áustria, Finlândia e Suécia, que iriam aderir a 1 de Janeiro de 1995, tornavase evidente que os países da Europa Central e de Leste, finda a Guerra Fria e capacitados para desenvolver a sua própria política externa, também pretendiam candidatar-se à adesão. Mas já anteriormente se haviam concretizado três rondas de alargamento (em 1973, 1981 e 1986) e, no futuro, se realizariam outras três (em 2004, 2007 e 2013). Assunto negligenciado no âmbito da teoria da integração regional e europeia até ao próprio alargamento a leste, a política do alargamento tem sido uma constante na agenda da UE e é mesmo considerada como "a mais bem sucedida política externa" da mesma. Este artigo pretende assim analisar a génese, a natureza e os traços evolutivos da política do alargamento da UE, socorrendo-se das características (semelhantes e/ou distintas) das diferentes rondas de alargamento.

Palavras-chave: política do alargamento; União Europeia

\section{Abstract}

In the 1990's, enlargement, first regarding the EFTA countries and then the Eastern European countries, dominated the European Union's (EU) agenda. While Austria, Finland and Sweden accession negotiations were still taking place, it became clear that, after the end of the Cold War and empowered to develop their own foreign policy, 
Central and Eastern European countries would also apply for membership. In the past, there had already occurred three enlargement rounds (in 1973, 1981 and 1986) and in the future three others (in 2004, 2007 and 2013). Neglected subject in the regional and European integration theory until the Eastern enlargement itself, the enlargement policy has always been on the EU's agenda and is even considered as "the most successful foreign policy" of the EU. This article will assess the origin, nature and evolution of the EU's enlargement policy, by comparing the similar or distinguish features of several enlargement rounds.

Keywords: enlargement policy; European Union

A história dos alargamentos da União Europeia (UE) ${ }^{1}$ começa com o pedido de adesão da Irlanda a 31 de Julho de 1961, logo seguido por pedidos semelhantes por parte da Dinamarca, da Noruega e do Reino Unido. Desde então até à data que o alargamento deixou de ser uma possibilidade plasmada nos tratados para unificar o continente europeu, sendo inclusive considerada pela própria UE como um dos seus 10 êxitos $^{2}$.

A política do alargamento é uma entre várias outras (por exemplo, agricultura e pesca, economia, finanças e fiscalidade, emprego e direitos sociais) políticas comuns da UE e a literatura tem acompanhado a questão, sobretudo em relação a cada ronda de alargamento $^{3}$, mas também particularmente a partir do alargamento aos países nórdicos

\footnotetext{
${ }^{1}$ Artigo baseado na comunicação "A mais bem sucedida política externa da União Europeia: a política do alargamento" apresentada no I Colóquio Internacional da Revista Debater a Europa, e concluído a 14 de Abril de 2014.

${ }^{2}$ COMISSÃO EUROPEIA - 10 Sucessos que Partilhamos na União Europeia. Lisboa: Comissão Europeia - Representação em Portugal, 2010.

${ }^{3}$ A título demonstrativo, ver por exemplo: GEDDES, Andrew - Britain and the European Union. London: Palgrave Macmillan, 2013. ISBN 978-0-230-29195-9; MILES, Lee and WIVEL, Anders - Denmark and the European Union. London: Routledge, 2013. ISBN 1135103259; LAURSEN, Johnny - A Kingdom Divided: Denmark. In KAISER, Wolfram and ELVERT, Jürgen (eds.) - European Union Enlargement A Comparative History. London: Routledge, 2004, pp. 31-52. ISBN 1134323859; MOXON-BROWNE, Eduard - From Isolation to Involvement: Ireland. In KAISER, Wolfram and ELVERT, Jürgen (eds.) European Union Enlargement - A Comparative History. London: Routledge, 2004, pp. 53-69. ISBN 1134323859; MOREIRA, Gillian Grace Owen - On the Margins of Europe: Britain and European integration (1945-1997). Aveiro: Universidade de Aveiro, 2000; DRUDY, P. J. and MCALEESE, Dermot - Ireland and the European Community. Cambridge: Cambridge University Press, 1984. ISBN -; TSALICOGLOU, Iacovos S. - Negotiating for Entry: The Accession of Greece to the European Community. Dartmouth: Dartmouth Publishing Company, 1995. ISBN 1855212277; KARAMOUZI, Eirini - Greece's path to EEC membership, 1974-1979: the view from Brussels. London: London School of Economics, 2011 [policopiado; tese de doutoramento]; CUNHA, Alice - O Alargamento Ibérico da Comunidade Económica Europeia: A Experiência Portuguesa. Lisboa: Universidade Nova de Lisboa, 2012 [policopiado; tese de doutoramento]; AAVV - Adesão de Portugal às Comunidades Europeias História e Documentos. Lisboa: Parlamento Europeu/Assembleia da República/Comissão Europeia, 2001. ISBN 972556300X; BORREGO, Alexandre Ferreira - Évolution des Rapports entre le Portugal et les
} 
em 1995 e na perspectiva do maior alargamento de sempre, o de 2004, numa perspectiva mais de conjunto e teórica. A este respeito, sublinham-se os trabalhos de Christopher Preston que analisa os principais assuntos levantados pelas sucessivas rondas de alargamento, com referências para o tradicional método comunitário e suas limitações, enquanto explora as experiências passadas e as lições que delas podem ser retiradas, assim como o impacto que o alargamento tem para com as políticas comuns, as instituições comunitárias e para os próprios novos Estados-membros; de Wolfram Kaiser e Jürgen Elvert que fazem uma análise comparada das políticas pró-europeias dos Estados que aderiram à Comunidade Económica Europeia (CEE)/UE de 1973 a 1995 inclusive; de Neill Nugent que providencia uma avaliação dos diferentes contextos históricos e teóricos em que as diferentes rondas de alargamento se realizaram e as suas implicações para a identidade, governança, economia, políticas comuns e papel

Communautés Européennes - Des Accords de Libre Échange à l'Adhésion. s. 1.: s. ed., 1979. ISBN. - ; NÚÑEZ PEÑAS, Vanessa - Entre la reforma y la ampliación (1976-1986): las negociaciones hispanocomunitarias en tiempos de transición y approfondissement. Madrid: Complutense University of Madrid, 2013 [policopiado; tese de doutoramento]; BASSOLS, Raimundo - España en Europa. Historia de la Adhesión (1957-1985). Madrid: Política Exterior, 1995. ISBN 8488025203; ALONSO, Antonio - España en el Mercado Común. Del Acuerdo del 70 a la Comunidad de los Doce. Madrid: Espasa-Calpe, 1985. ISBN -; BISCHOF, Günter, PELINKA, Anton, GEHLER, Michael - Austria in the European Union. Washington: Transaction Publishers, 2002. ISSN 0765808994; KUOSMANEN, Antti, BOLLEN, Frank and NICOLAIDES Phedon - Finland's journey to the European Union. Maastricht: European Institute of Public Administration, 2001. ISBN 13 978-90-6779-154-0; LUIF, Paul - On the road to Brussels: the political dimension of Austria's, Finland's, and Sweden's accession to the European Union. Wien: Braumüller, 1995. ISBN 3700311214,; BALDWIN, Richard, HAAPARARANTA, Pertti and KIANDER, Jaakko - Expanding Membership of the European Union. Cambridge: Cambridge University Press, 1995. ISBN 0521481341; SAJDIK, Martin and SCHWARZINGER, Michael - European Union Enlargement: Background, Developments, Facts. New Brunswick: Transaction Publishers, 2008. ISBN ISBN 1412806674; RUPNIK, Jacques and ZIELONKA, Jan (eds.) - The Road to the European Union - The Czech and Slovak Republics. Manchester: Manchester University Press, vol. 1, 2003. ISBN 978-0-71906597-2; BARBÉ, Esther and JOHANSSON-NOGUÉS, Elisabeth (eds.) - Beyond Enlargement: The New Members and New Frontiers of the Enlarged European Union. Barcelona: Institut Universitari d'Estudis Europeus, 2003. ISBN 8495201127; PETTAI, Vello and ZIELONKA, Jan (eds.) - The Road to the European Union - Estonia, Latvia and Lithuania. Manchester: Manchester University Press, vol. 2, 2003. ISBN 0719065615; BOJKOV, Victor D. - Neither here, not there: Bulgaria and Romania in current European politics. Communist and Post-Communist Studies. California: Elsevier Ltd. ISSN 0967-067X. Volume 37, Issue 4 (2004), pp. 509-522; ANDREEV, Svetlozar A. - The unbearable lightness of membership: Bulgaria and Romania after the 2007 EU accession. Communist and Post-Communist Studies. California: Elsevier Ltd. ISSN 0967-067X. Volume 42, Issue 3 (2009), pp. 375-393; JOVIĆ, Dejan - Croatia and the European Union: a long delayed Journey. Journal of Southern Europe and the Balkans. London: Taylor \& Francis. ISSN 1461-3190. Volume 8, Number 1 (2006), pp. 85-103; OTT, Katarina (ed.) - Croatian Accession to the European Union: Facing the Challenges of Negotiations, vol 3. Zagreb: Institute of Public Finance, 2005. ISBN: 953-6047-58-6; MASSARI, Maurizio - Do All Roads Lead to Brussels? Analysis of the Different Trajectories of Croatia, Serbia-Montenegro and BosniaHerzegovina. Cambridge Review of International Affairs. Cambridge: Centre of International Studies. ISSN 0955-7571. Volume 18, Issue 2 (2005), pp. 259-273. 
internacional da UE; e de Lorena Ruano que analisa a história dos procedimentos das negociações de adesão ${ }^{4}$.

Já os trabalhos de Graham Avery e Fraser Cameron exploram o processo de alargamento a 10 Estados da Europa Central e de Leste; e o de Michael J. Baun reflecte acerca da decisão da UE de um novo alargamento, da definição de uma estratégia de pré-adesão para os candidatos, e aponta explicações sobre o complexo processo de decisão comunitário, os limites do alargamento e as consequências daí advenientes para o futuro da própria $\mathrm{UE}^{5}$.

E, mais recentemente, no final da última década, são de destacar as contribuições de Geoffrey Pridham sobre o surgimento dos Estudos sobre o alargamento como uma nova área de estudo no âmbito dos Estudos Europeus; de Frank Schimmelfennig e Ulrich Sedelmeier acerca das mais recentes teorizações do estudo do alargamento, baseando-se sobretudo nas percepções recentes da literatura emergente teóricoconceptual relativa ao alargamento a leste, combinando essa mesma abordagem teórica com uma análise comparativa (apoia-se em debates teóricos mais abrangentes e as suas implicações para o alargamento da UE, no contexto mais alargado da adesão a organizações internacionais); de Christina J. Schneider sobre as tensões e os conflitos emergentes de cada ronda de alargamento, nas quais os Estados-membros receiam perder benefícios, e os ganhos redistributivos; e, finalmente, de Christophe Hillion a respeito da instrumentalização da política do alargamento pelos Estados-membros em favor das suas respectivas agendas políticas nacionais e de ganhos domésticos ${ }^{6}$.

Nos anos 90, a questão do alargamento, primeiro dos países nórdicos e depois dos de leste, dominou a agenda da UE. Enquanto ainda se negociava a adesão da Áustria, Finlândia e Suécia, que iriam aderir a 1 de Janeiro de 1995, tornava-se evidente que os países da Europa Central e de Leste, finda a Guerra Fria e capacitados para desenvolver a sua própria política externa, também pretendiam candidatar-se à adesão. Mas já anteriormente se haviam concretizado três rondas de alargamento (em 1973,

\footnotetext{
${ }^{4}$ PRESTON, Christopher - Enlargement and Integration in the European Union; KAISER, Wolfram and ELVERT, Jürgen (eds.) - European Union Enlargement - A Comparative History; NUGENT, Neill (ed.) European Union Enlargement; RUANO, Lorena - Origins and Implications of the European Union's Enlargement Negotiations Procedure.

${ }^{5}$ AVERY, Graham and CAMERON, Fraser - The Enlargement of the European Union; BAUN, Michael J. - A Wider Europe: The Process and Politics of European Union Enlargement.

6 PRIDHAM, Geoffrey - The Arrival of Enlargement Studies: Patterns and Problems; SCHIMMELFENNIG, Frank and SEDELMEIER, Ulrich (eds.) - The Politics of European Union Enlargement: Theoretical Approaches; SCHNEIDER, Christina J. - Conflict, Negotiation and European Union Enlargement; HILLION, Christophe - The Creeping Nationalisation of the EU Enlargement Policy.
} 
1981 e 1986) e, no futuro, se realizariam outras três (em 2004, 2007 e 2013). Assunto negligenciado no âmbito da teoria da integração regional e europeia até ao próprio alargamento a leste, a política do alargamento tem sido uma constante na agenda da UE e é mesmo considerada como "a mais bem sucedida política externa" da mesma. Este artigo pretende assim analisar a génese, a natureza e os traços evolutivos da política do alargamento da UE, socorrendo-se das características (semelhantes e/ou distintas) das diferentes rondas de alargamento, numa vertente mais pedagógica, didática.

\section{A génese (da política do alargamento)}

Na reconstrução da Europa pós Segunda Guerra Mundial, o Reino Unido tornou claro que não participaria em nenhuma organização com características supra-estaduais. Com uma história de potência mundial, detentora de uma vasto império, era impensável para a elite política britânica aderir a qualquer organização europeia de índole supraestadual, pelo que, voluntariamente, se excluiu da fundação da CEE.

Será apenas depois da constituição e da entrada em funcionamento em 1960 da European Free Trade Association (EFTA), idealizada precisamente pelo próprio Reino Unido e por oposição à CEE, que irão surgir os primeiros pedidos de adesão à CEE. Através da Convenção de Estocolmo pretendia-se constituir uma zona de livre câmbio, à semelhança da do Mercado Comum, imitando a política de desarmamento alfandegário e esperando conseguir negociar mais favoravelmente com a CEE formas de associação ou de adesão de modo a não coexistirem dois blocos económicos europeus distintos.

Quando se iniciaram as negociações para a constituição de uma união aduaneira, na origem da futura CEE, a atitude de indiferença do Reino Unido transformou-se em preocupação, e logo em oposição à criação da mesma. É neste contexto que surge, por iniciativa do Reino Unido, a EFTA. Contudo, como refere Wolfram Kaiser, o Reino Unido nem nunca considerou a EFTA como um fim em si mesmo, nem esta foi útil para a prossecução de objectivos políticos britânicos mais abrangentes, pelo que, a 3 de Maio de 1960, quando a Convenção de Estocolmo entrou em vigor, já o Reino Unido havia começado a reformular a sua relação com a $\mathrm{CEE}^{7}$.

\footnotetext{
${ }^{7}$ KAISER, Wolfram - What Alternative is Open to Us?': Britain. pp. 14-19.
} 
Neste encadeamento, menos de um ano depois, a 9 de Agosto de 1961, já o Reino Unido solicitava a adesão. O pedido de adesão britânico não seguiu sozinho. Por essa mesma altura, a Dinamarca, a Irlanda e a Noruega seguiram o exemplo ${ }^{8}$. A Irlanda fê-lo, sobretudo, de modo a proteger as suas exportações agrícolas, no âmbito da Política Agrícola Comum, para o Reino Unido, assim como antevia a possibilidade de modernizar o país. Em relação à Dinamarca, desde o início da CEE que o país mantinha contactos frequentes com a mesma, tendo sido a Dinamarca a convencer o Reino Unido, de quem estava totalmente dependente em termos de comércio ${ }^{9}$, a apresentar um pedido conjunto de adesão, o qual constituía "a melhor solução a longo-prazo, combinando os dois maiores mercados para a produção agrícola dinamarquesa, também oferecendo vantagens a longo-prazo para as exportações industriais" ${ }^{10}$.

Estes pedidos de adesão não surgem, todavia, desenquadrados do espírito e do que se passava no seio da CEE. Desde o início da CEE que a mesma teve um carácter de abertura em relação a possíveis adesões posteriores (artigo 237..$^{\circ}$ do Tratado de Roma) e no Conselho Europeu de Paris, realizado entre 10 e 11 de Fevereiro de 1961, os Estados-membros diziam-se desejosos de encontrar formas de manter e fomentar o comércio com os outros países europeus, e ainda que havia a possibilidade de alargar a CEE a outros membros no futuro ${ }^{11}$.

Todavia, o veto do presidente francês Charles De Gaulle à candidatura britânica nesse mesmo ano terminou com as negociações mesmo antes de estas se terem iniciado. $\mathrm{O}$ veto do general De Gaulle, que não incluía nas prioridades da sua agenda política internacional a $\mathrm{CEE}^{12}$, à intenção do Reino Unido aderir à CEE, a 14 de Janeiro de 1963, evocando que a adesão de novos membros modificaria fortemente a natureza dos tratados e que o Reino Unido estava pouco empenhado politicamente com a adesão, tinha, também, subjacentes dois outros motivos: os interesses económicos dos britânicos e a sua orientação política atlantista, com os laços que o uniam aos Estados Unidos da América.

\footnotetext{
${ }^{8}$ Em verdade, o primeiro pedido de adesão a ser apresentado não foi o britânico, mas o irlandês, apresentado dias antes, com a certeza, porém, de que o Reino Unido iria submeter o seu pedido. Assim, a Irlanda entregou o pedido de adesão a 31 de Julho de 1961; a Dinamarca a 10 de Agosto de 1961; e a Noruega a 30 de Abril de 1962.

${ }^{9}$ LAURSEN, Johnny - A Kingdom Divided: Denmark, p. 33.

${ }^{10}$ ELVERT, Jürgen - A Fool's Game or a Comedy of Errors?: EU Enlargements in Comparative Perspective, p. 195.

${ }^{11}$ Conclusions of the Conferences of the Heads of State or of Government (Summit), 1961-1974. Paris, 10 and 11, February, 1961. Communique. [Em linha]. Consultado a 17/03/2014. Disponível em WWW: http://aei.pitt.edu/1463.

${ }^{12}$ PARSONS, Craig - A Certain Idea of Europe, p. 119.
} 
Resolvida a "crise da cadeira vazia", que pôs em confronto duas visões distintas de orientação da CEE (a supra-estadual e a intergovernamental) e vencidos dois anos (1963-65) de crise na CEE, o Reino Unido, através do governo trabalhista de Harold Wilson, submete um novo pedido de adesão, a 11 de Maio de 1967. Mais uma vez este pedido é acompanhado pelos da Dinamarca, Irlanda, Noruega e também da Suécia ${ }^{13}$. Mais uma vez, o pedido britânico é vetado pela França ${ }^{14}$.

Entretanto, com a demissão do presidente francês, a França passa a estar liderada por Georges Pompidou, que convoca uma conferência dos chefes de Estado e de Governo a realizar-se entre 1 e 2 de Dezembro de 1969, em Haia, cujo objectivo principal era o de relançar o processo de integração europeu. A Cimeira de Haia marca precisamente a história da CEE, com a adopção do tríptico acabamento, alargamento, aprofundamento.

Para este artigo interessa-nos sobretudo o segundo desses objectivos, o do alargamento. Nesse âmbito, houve acordo quanto ao ingresso de novos membros. Como se pode ler no comunicado final dessa cimeira, os chefes de Estado e de Governo reafirmaram o seu acordo sobre o princípio do alargamento. Chama-se aqui, desde já, a atenção para o facto de o alargamento na altura ser ainda considerado um princípio, ou um procedimento, apenas tendo adquirido o estatuto de política aquando do alargamento à Europa Central e de Leste três década mais tarde.

Será também nesta cimeira que se adoptam alguns critérios fundamentais para as futuras negociações, como sejam, a aceitação dos tratados, dos seus objectivos políticos e de todo o acervo comunitário, além das decisões relativas ao desenvolvimento (aprofundamento) da CEE. Ainda de acordo com as conclusões da cimeira, o trabalho preparatório deveria começar logo que possível e "no espírito mais positivo", sendo assim, oficialmente quatro os candidatos ao primeiro alargamento da CEE: a Dinamarca, a Irlanda, a Noruega e o Reino Unido, cujas negociações de adesão começaram a meio do ano seguinte, foram concluídas em 1972, tendo-se concretizado o primeiro alargamento em 1973.

\footnotetext{
${ }^{13}$ A Irlanda e Reino Unido a 11 de Maio de 1967; Dinamarca no dia seguinte; Noruega a 21 de Julho de 1967. Um novo Estado surge nesta segunda ronda de pedidos, a Suécia, que entrega o seu pedido a 28 de Julho de 1967.

${ }^{14}$ Conférence de presse du général de Gaulle - Paris: Pathé Journal [Prod.], 27.11.1967. Pathé Archives, Saint-Ouen. - FILM (00:03:08, Black and White, Original Sound Track). [Em linha]. Consultado a 17/03/2014. Disponível em WWW: http://www.ena.lu/.

De Gaulle rejeitou a segunda candidatura britânica essencialmente pelas mesmas razões da primeira vez: relacionamento anterior do Reino Unido com a CEE; tentativa de submergir a CEE numa área aduaneira livre alargada; a relação privilegiada do Reino Unido com os Estados Unidos da América.
} 
Desde a primeira ronda de alargamento que a CEE/UE tem crescido em número de Estados-membros: dos seis membros iniciais quase que já quintuplicou esse número, com os actuais 28 membros e sete rondas de alargamento.

\section{Rondas do alargamento}

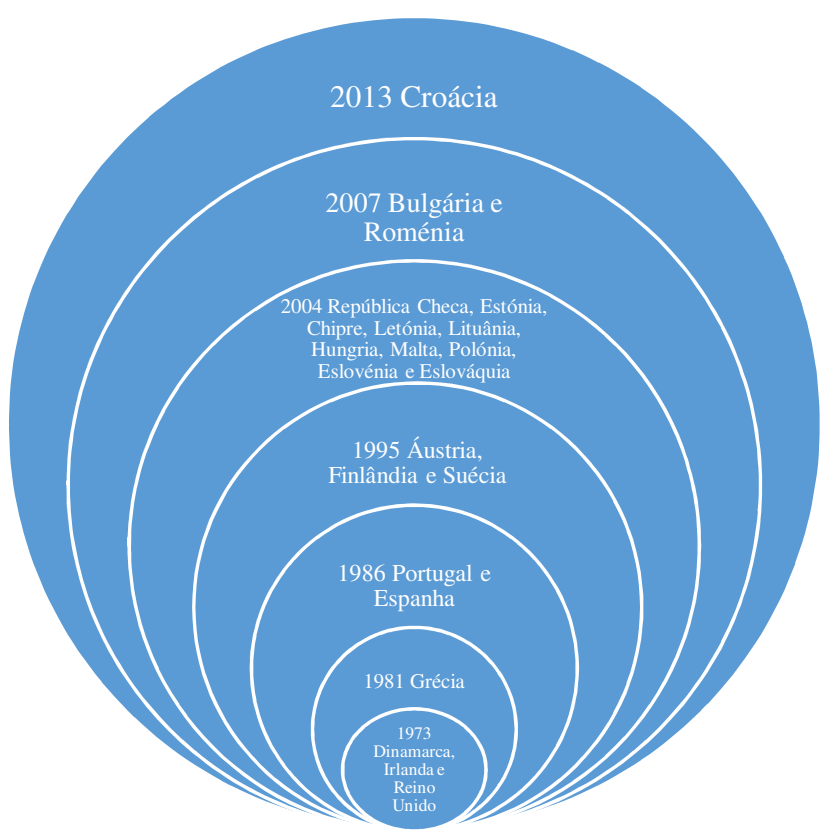

Fonte: elaboração própria.

Todas as rondas foram diferentes umas das outras por motivos políticos, económicos e estratégicos, que lhes estavam subjacentes. Contudo, o alargamento tem figurado na ordem do dia da UE quase como um item permanente, embora não seja um assunto "particularmente popular"15.

De facto, embora o alargamento ibérico da CEE a Portugal ${ }^{16}$ e a Espanha em 1986 não tenha sido um facto particularmente marcante para a própria CEE e seus Estados-membros, e o processo negocial tenha decorrido dentro da "normalidade" comunitária, a adesão foi a mais importante negociação política-económica-diplomática que Portugal teve no passado recente. E os portugueses têm sido precisamente dos europeus mais favoráveis ao alargamento da UE, sendo que mais de metade (55\%)

\footnotetext{
${ }^{15}$ SCHNEIDER - Conflict, Negotiation ..., p. 1.

${ }^{16}$ Sobre o processo de adesão de Portugal, consultar: Cunha, Alice - O Alargamento Ibérico da Comunidade Económica Europeia: A Experiência Portuguesa. Lisboa: Faculdade de Ciências Sociais e Humanas, 2012 [policopiado].
} 
apoiava o alargamento à Europa Central e de Leste contra $42 \%$ da média da $\mathrm{UE}^{17}$. Já anteriormente, aquando do alargamento de 1995, entre 63 a $68 \%$ dos portugueses eram a favor da adesão da Áustria, Finlândia e Suécia, contra apenas 5 a $6 \%$ que eram contra $^{18}$.

Actualmente são candidatos à adesão a antiga república jugoslava da Macedónia, a Islândia, o Montenegro, a Sérvia e a Turquia. A Turquia é um caso paradigmático. O envolvimento da Turquia com a integração europeia remonta a 1959 e inclui o Acordo de Associação de Ankara (1963) para o estabelecimento progressivo de uma união aduaneira (concretizado apenas em 1995). Em 1987, a Turquia apresentou o pedido de adesão à então CEE e, em 1997 foi declarada elegível para aderir à UE. Na verdade, as negociações de adesão apenas começaram em 2005, mas até que a Turquia se comprometa a aplicar o Protocolo Adicional do Acordo de Associação de Ancara a Chipre, oito capítulos negociais não serão abertos e nenhum capítulo será fechado mesmo que provisoriamente. De resto, é o facto de a Turquia ser um país de grande dimensão, pouco desenvolvido e muçulmano que sobretudo transformam a adesão turca num grande desafio, que levanta ansiedades e resistências em muitos Estados-membros.

Da lista de candidatos potenciais constam a Albânia, a Bósnia Herzegovina e o Kosovo.

Por outro lado, também é interessante verificar a questão da "desunião" ou da saída voluntária de um Estado-membro da UE, encontrando-se tal consagrado, pela primeira na história da UE, no artigo 50 do Tratado de Lisboa, que estipula que "qualquer Estado--membro pode decidir, em conformidade com as respectivas normas constitucionais, retirar-se da União", sendo negociado e posteriormente celebrado entre a UE e esse Estado "um acordo que estabeleça as condições da sua saída".

Conquanto a saída da UE já fosse possível antes da ratificação do Tratado de Lisboa, ainda que não estivesse, nem esteja, em sintonia com a própria razão de ser do projecto de unificação europeia ${ }^{19}$, a mesma já se havia verificado em parte com a saída da Gronelândia a 1 de Fevereiro de $1985^{20}$, em parte porque a Gronelândia não era um Estado-membro da CEE, mas uma parte de um Estado-membro, a Dinamarca, logo

\footnotetext{
${ }^{17}$ EUROPEAN COMMISSION, Eurobarometer 61, p. 55.

${ }^{18}$ EUROPEAN COMMISSION, Eurobarometer No. 42, p. B.36.

${ }^{19}$ ATHANASSIOU, Phoebus - Withdrawal and Expulsion from the EU and EMU: Some Reflections. Sobre esta questão, ler também: PATRÃO, Afonso - A flexibilidade na União Europeia quanto ao estatuto de membro: o direito de abandonar a União. Debater a Europa. Aveiro: Centro de Informação Europe Direct de Aveiro-CEIS20. ISSN 1647-6336. N.8 Janeiro/Julho 2013.

${ }^{20}$ COMISSÃO - Boletim das Comunidades Europeias, N. ${ }^{\circ} 2$, p. 16.
} 
apenas se pode considerar como uma redução de tamanho de um Estado-membro e não a saída efectiva de um.

Mesmo existindo agora formalmente essa possibilidade, os grandes custos económicos associados a uma saída, assim como as mudanças legislativas e constitucionais feitas após a adesão podem per se excluir a saída como opção realista ${ }^{21}$, não sendo provável de resto que aconteça alguma saída nos próximos anos. No entanto, esta opção não deve ser mesmo assim subestimada, na medida em que um Estadomembro colocado perante uma diminuição dos seus benefícios pode efectivamente solicitar compensações utilizando o direito de saída ${ }^{22}$.

\section{A natureza e os traços evolutivos}

A política do alargamento é uma política comum que "lida com os países aspirantes a Estados membros da União Europeia", incorporando "condições estritas de adesão", de modo a assegurar que os novos membros sejam admitidos apenas quando estejam capacitados para cumprir as obrigações decorrentes da adesão, o que inclui a incorporação de todo o acervo comunitário que, para efeitos de negociações de adesão está actualmente dividido em 35 capítulos (nomeadamente liberdade de circulação de bens, capitais e pessoas, política de concorrência, fiscalidade, educação e cultura, ambiente, ...).

Até se chegar a este ponto de situação, tem sido percorrido um caminho de aperfeiçoamento das regras inerentes ao processo de alargamento. Originalmente, o Tratado de Roma (1957) já previa esta situação, no seu artigo $237 .^{\circ}$, que estipula que "qualquer Estado europeu pode pedir para se tornar membro da Comunidade". Se o Tratado de Roma por um lado prevê a hipótese de alargamento a novos membros e estabelece quatro princípios básicos (apresentação do pedido ao Conselho, obrigatoriedade do parecer da Comissão, decisão por voto unânime e ratificação do tratado de adesão por todas as partes), por outro não especifica mais detalhes de como o processo negocial se desenrolará até à concretização efectiva do alargamento. Tal só irá realmente acontecer aquando da recepção dos primeiros pedidos de adesão em 1961, o

\footnotetext{
${ }^{21}$ BERGLUND, Sara - Prison or voluntary cooperation? The possibility of withdrawal from the European Union, pp. 147-167.

${ }^{22}$ LECHNER, Susanne and OHR, Renate - The right of withdrawal in the treaty of Lisbon: a game theoretic reflection on different decision processes in the EU, pp. 357-375.
} 
que obrigará a CEE a reflectir sobre os procedimento e a definir concretamente os mesmos.

A este respeito, o Relatório Birkelbach ${ }^{23}$, de 1961, estabelece como condições prévias da adesão factores: (1) geográficos - só Estados europeus podem aspirar a ser membros; (2) económicos - capacidade para prosseguir os objectivos económicos da CEE; e (3) políticos - existência de uma forma de Estado democrático. Já o Relatório Davignon $^{24}$, de 1970 , no seu ponto 5., preconiza uma Europa baseada no respeito pela liberdade e pelos direitos humanos, que una Estados democráticos com parlamentos eleitos.

Após estes primeiros relatórios, seria apenas já na década de 90 que haveria novos desenvolvimentos, primeiro com o Tratado da União Europeia ou de Maastricht (1993), que mantém o princípio do alargamento, acrescentando aos critérios anteriores a necessidade de também se obter a concordância da maioria dos membros do Parlamento Europeu (artigo O), e depois com a adopção dos Critérios de Copenhaga nesse mesmo ano.

Os Critérios de Copenhaga foram estabelecidos no Conselho Europeu em Copenhaga (12 e 13 de Dezembro de 1993) e determinam que qualquer Estado que pretenda aderir à UE tem de preencher três requisitos essenciais: (1) possuir "instituições estáveis que garantam a democracia, o Estado de Direito e o respeito pelos direitos humanos, bem como o respeito pelas minorias e a protecção das mesmas"; (2) "ter uma economia de mercado plenamente operacional, bem como capacidade para fazer face à pressão da concorrência e das forças de mercado no interior da União Europeia"; e (3) "capacidade para assumir as obrigações decorrentes do estatuto de Estado-membro da União Europeia, nomeadamente para aderir aos objectivos da união política, económica e monetária". A estes critérios foi acrescentado um outro, saído do Conselho Europeu de Madrid (15 e 16 de Dezembro de 1995) que estipula que o candidato deve estar numa situação que lhe permita aplicar a regulamentação e os procedimentos da UE, através de estruturas administrativas e judiciais apropriadas.

\footnotetext{
${ }^{23}$ Rapport fait au nom de la commission politique sur les aspects politiques et institutionnels de l'adhésion ou de l'association à la Communauté par M. Willi Birkelbach Rapporteur, Services des publications des Communautés européennes, s. 1., 1962. [Em linha]. Consultado a 17/03/2014. Disponível em WWW: http://www.ena.lu/.

24 "Davignon Report", in Bulletin of the European Communities, 1970, No 11, pp. 9-14. [Em linha]. Consultado a 17/03/2014. Disponível em WWW: http://www.ena.lu/.
} 
A estes critérios junta-se igualmente a capacidade da UE para receber novos membros, tendo esta de reunir condições para os integrar não descurando os projectos em curso, pelo que se reserva o direito de estabelecer o momento em que esteja preparada para os receber.

Mais recentemente, o Tratado de Lisboa impõe como condição para uma candidatura não apenas o respeito pelos valores fundamentais ${ }^{25}$ em que a própria UE se baseia mas também o empenho na sua promoção, assim como refere que para o processo de adesão "são tidos em conta os critérios de elegibilidade aprovados pelo Conselho Europeu" (artigo 49), ou seja, a qualquer momento o Conselho Europeu pode acrescentar novas prerrogativas.

Todavia, estes critérios não são os únicos a ditarem a adesão de um Estado, na medida em que existem condicionalismos no próprio acervo comunitário, nas conclusões dos conselhos europeus, este último agora incorporado no Tratado de Lisboa, como mencionado acima, o que eleva a fasquia dos potenciais candidatos à adesão, sendo inclusive de referir que já se discute em Bruxelas a oportunidade de alterar os Critérios de Copenhaga.

É amplamente reconhecido que a adesão da Bulgária e da Roménia em 2007 foi precipitada, não tendo sido precedida de uma preparação adequada, de tal modo que ambos os Estados estão sujeitos ao Mecanismo de Cooperação e Verificação, um instrumento inédito e desenhado especificamente para garantir a sustentabilidade pósadesão de determinadas reformas nesses Estados. Porém, problemas recorrentes como o precário funcionamento das instituições democráticas, a corrupção e o crime organizado, têm contribuído para se prolongar um certo "período de nojo" em relação ao alargamento, que se prevê que perdure nos próximos anos.

Tendo em consideração esta experiência não tão bem sucedida, já as negociações com a Croácia foram mais pensadas, tendo sido entretanto introduzidos novos mecanismos de monitorização, com a introdução de cláusulas de salvaguarda, mais procedimentos de rotina para suspender as negociações e mais exigência na consolidação das reformas empreendidas. Enquanto anteriormente algumas questões

\footnotetext{
${ }^{25}$ Artigo 2. ${ }^{\circ}$ do Tratado de Lisboa: "A União funda-se nos valores do respeito pela dignidade humana, da liberdade, da democracia, da igualdade, do Estado de direito e do respeito pelos direitos do Homem, incluindo os direitos das pessoas pertencentes a minorias. Estes valores são comuns aos EstadosMembros, numa sociedade caracterizada pelo pluralismo, a não discriminação, a tolerância, a justiça, a solidariedade e a igualdade entre homens e mulheres.
} 
ficavam pendentes para o pós-adesão, de momento a UE é inflexível em lidar com as mesmas antes do alargamento.

Neste ponto, importa considerar se as características do processo de alargamento têm sido únicas ou repetidas? Embora se possa afirmar com precisão que cada ronda de alargamento tem sido única, existem algumas semelhanças entre elas. Desde logo, é um processo motivado pela política nacional do candidato, ou seja, a decisão de solicitar a adesão é da inteira responsabilidade do candidato, sendo que a UE não convida nenhum Estado a apresentar a candidatura, embora alguns Estados possam ter sido encorajados a fazê-lo ou tenham tido ao longo do processo negocial o "patrocínio" de algum Estadomembro (por exemplo o "apadrinhamento" da candidatura grega pelo governo francês).

Segundo, os incentivos para a adesão têm sido de ordem política (consolidação democrática), geopolítica (posicionamento estratégico) e económica (concessões comerciais, participação num mercado alargado).

Terceiro, e finalmente, o processo de adesão em si, que tem permanecido substancialmente igual ao concebido aquando do primeiro alargamento e que apenas tem sido adaptado às circunstâncias do tempo em que decorre. Lorena Ruano analisa o procedimento de negociação do alargamento, aspecto muitas vezes negligenciado, mas que tem influenciado todas as rondas de alargamento. Como refere a autora, embora conste do próprio Tratado de Roma, apenas seria propriamente definido em 1961, aquando dos primeiros pedidos de adesão. Tendo em consideração as características próprias do primeiro alargamento, assim como as circunstâncias históricas, resultou um procedimento negocial que beneficiava os arranjos existentes em detrimento do acolhimento de novos Estados-membros. Tendo tal em consideração, percebe-se que tenham sido definidos três aspectos importantes que foram aplicados nos alargamentos seguintes, sendo eles: (1) as negociações são conduzidas segundo o método bilateral (a CEE define a agenda, e negoceia de acordo com o seu método de decisão); (2) a adopção do acervo comunitário com um mínimo de derrogações; e (3) as negociações tendentes ao alargamento não devem prejudicar o aprofundamento da $\mathrm{CEE}^{26}$.

A estes aspectos, Christopher Preston acrescenta, além da adopção do acervo comunitário referido acima, mais cinco princípios implícitos que determinam o processo negocial, sendo eles os seguintes: (1) as negociações focam-se exclusivamente na forma de adopção do acervo pelos candidatos (períodos de transição, harmonização legal e

\footnotetext{
${ }^{26}$ RUANO - Origins and Implications..., p. 1.
} 
fiscal); (2) os problemas resultantes da crescente diversidade da Comunidade alargada são resolvidos através da criação de novas políticas em detrimento de reformular os mecanismos existentes e suas deficiências (exemplo: criação do Plano Integrado do Mediterrâneo para compensar os agricultores gregos, franceses e italianos aquando do alargamento ibérico); (3) os novos Estados-membros são integrados no sistema institucional existente com adaptações limitadas, com a promessa de uma revisão mais substancial após o alargamento (debates sobre os procedimentos de tomada de decisão, eficiência e responsabilidade); (4) a CEE prefere negociar com grupos de Estados que já tenham relações próximas entre si; e (5) os Estados-membros usam o processo de alargamento para, individualmente, perseguir os seus interesses e, colectivamente, para evidenciar os problemas internos ${ }^{27}$.

O formato bilateral das negociações, em que são os Estados-membros, de acordo com uma posição comum, que negociam com o candidato, e com cada um individualmente, é baseado numa fórmula que protegia as regras da Comunidade e os interesses dos Estados-membros. Desta opção resultaram várias consequências de entre as quais a posição cimeira dos Estados-membros que estabelecem a agenda, as posições comunitárias são inflexíveis, virtualmente não negociáveis, e as estruturas internas e os procedimentos de tomada de decisão também são projectados para as negociações ${ }^{28}$, o que permite que cada ronda de alargamento tenha passado por um processo de negociação similar e previsível, e que os candidatos se encontrem sistematicamente numa posição mais fraca em relação aos Estados-membros, daí que façam várias concessões em troca da adesão",29.

As rondas de alargamento têm, assim, sido conformes ao método comunitário clássico, com as negociações a centrarem-se exclusivamente na adopção do acervo comunitário por parte dos candidatos e, logo, a negociar-se somente períodos de transição, não sendo previsível nenhuma alteração substancial a esse método ${ }^{30}$.

Apesar de desenvolvimentos verificados desde o primeiro alargamento, dos quais destacamos o estabelecimento dos Critérios de Copenhaga e a criação da Direcção-Geral do Alargamento na Comissão durante a presidência de Romano Prodi (1999-2004), cujo comissário é desde Fevereiro de 2010 Štefan Füle precisamente de

\footnotetext{
${ }^{27}$ PRESTON - Enlargement and Integration ..., pp. 18-22.

${ }^{28}$ RUANO - Origins and Implications ..., pp. 5-26.

${ }^{29}$ MORAVCSIK, Andrew and VACHUDOVA, Milada Anna - National Interests, State Power, and EU Enlargement, p. 44.

${ }^{30}$ PRESTON - Enlargement and Integration ...; PRESTON, Christopher - Obstacles to EU Enlargement: The Classical Community Method and the Prospects for a Wider Europe, pp. 451-463.
} 
um dos Estados-membros mais recentes, a República Checa, os mecanismos e procedimentos utilizados para com o alargamento têm sido basicamente sempre os mesmos ${ }^{31}$.

Se considerarmos a integração como "um processo e não um 'Estado-final', muitos aspectos desse processo foram consolidados em estruturas, regras e práticas que têm permanecido" 32 . Nesse sentido, e no que diz respeito em particular às negociações de adesão de Portugal, decorridas entre 1978 e 1985, em que o procedimento adoptado era bastante simples: uma delegação pronunciava a sua posição e a outra tomava conhecimento da mesma, com o propósito de reflectir sobre ela e de dar a sua resposta em momento posterior, actualmente uma negociação de adesão é muito mais complexa e contempla duas etapas fundamentais: (1) mandato e enquadramento - estabelecimento de um mandato negocial e um guia para as negociações; (2) análise e monitorização exame detalhado de cada capítulo (screening), de modo a serem aferidas as dificuldades existentes, e aferição permanente até à adesão dos progressos alcançados no sentido do candidato adoptar a legislação comunitária (monitoring). Deste modo, e ao contrário das primeiras rondas de alargamento em que todo o processo era, de certo modo, mais simplificado mas não menos institucionalizado e burocratizado, de momento, os candidatos têm que demonstrar a sua capacidade para cumprirem plena e harmoniosamente as suas responsabilidades enquanto Estado-membro.

Porém, no final, como defende Christina Schneider nestas negociações os candidatos e os Estados-membros negociam sobretudo a distribuição dos ganhos e das perdas do alargamento entre eles; assim como sustenta a tese que a UE se alarga perante grandes conflitos distributivos quando alguns membros, que podem vetar a adesão de novos membros, são compensados pelas suas perdas esperadas ${ }^{33}$. Acrescenta ainda que os Estados que mais têm a perder são os que têm incentivos para atrasar as negociações, podendo usar o seu poder de veto (uma vez que o alargamento requer unanimidade), de forma explícita ou implícita, até os Estados-membros que mais têm a ganhar com o alargamento os incentivarem, compensando-os com outros benefícios, de modo a superar essas perdas, tendo sido disso exemplo, no caso do alargamento ibérico, a França e a Itália, que apoiavam o alargamento, mas que queriam compensações no âmbito da Política Agrícola Comum.

\footnotetext{
${ }^{31}$ NUGENT, Neill - Distinctive and Recurring Features of Enlargement Rounds, p. 60

${ }^{32}$ CAPORASO, James A. - Regional Integration Theory: Understanding Our Past and Antecipating Our Future, p. 334.

${ }^{33}$ SCHNEIDER - Conflict, Negotiation ..., p. 183.
} 


\section{Os estudos sobre o alargamento}

O alargamento, considerado como "a mais bem sucedida política externa" da UE, tem contribuído para a consolidação democrática, respeito pelos direitos humanos, resolução de conflitos e estabilidade na Europa de Leste ${ }^{34}$ e sempre fez parte da "missão histórica" da CEE/UE ${ }^{35}$, mas até recentemente escasseava o seu suporte teórico.

Pesem embora a presença e o domínio desta questão na agenda da UE, no âmbito da teoria da integração regional, o alargamento foi um assunto negligenciado até ao próprio alargamento a leste. Enquanto as primeiras três rondas de alargamento deram lugar a estudos sobre a adesão dos Estados de um ponto de vista individual ou de conjunto (ronda), a partir do alargamento de 1995 aos Estados da EFTA e, sobretudo, com o alargamento aos países da Europa Central e de Leste, começaram a surgir os primeiros trabalhos orientados para a produção de teoria ${ }^{36}$.

Dada a extensão de análises teóricas e de formulação de teorias sobre a integração europeia, Michael Baun considera inclusive surpreendente que tenha havido pouco esforço para teorizar sobre a política do alargamento da $\mathrm{UE}^{37}$ e Helen Wallace congratula-se com o facto de o alargamento se ter tornado num "objecto de reflexões teóricas", sendo este desenvolvimento no âmbito dos Estudos Europeus "tanto bemvindo como há muito esperado" 38 , se bem que essa teorização ainda esteja "na sua infância" 39 .

Por outro lado, as teorias clássicas da integração, como o neofuncionalismo e o intergovernamentalismo, não foram inicialmente concebidas para analisar o processo de alargamento $^{40}$, se bem que as mesmas foram concebidas antes de se pensar sequer no primeiro alargamento.

Frank Schimmelfennig e Ulrich Sedelmeier ${ }^{41}$, ao analisarem a literatura sobre o alargamento, definem quatro dimensões do mesmo: (1) a política de alargamento do candidato (o que faz com que um Estado procure a adesão); (2) a política de

\footnotetext{
${ }^{34}$ SCHIMMELFENNIG, Frank - EU Political Accession Conditionality after the 2004 Enlargement: Consistency and Effectiveness, p. 918.

${ }^{35}$ PRESTON - Enlargement and Integration ..., p. 3.

${ }^{36}$ SCHIMMELFENNIG and SEDELMEIER- The Politics of EU ..., p. 4.

${ }^{37}$ BAUN - A Wider Europe ..., p. 15.

${ }^{38}$ WALLACE, Helen - Enlarging the European Union: Reflections on the Challenge of Analysis, p. 287.

${ }^{39}$ PRIDHAM - The Arrival of Enlargement ..., p. 17.

${ }^{40}$ MILES, Lee - Theoretical Considerations, p. 253.

${ }^{41}$ SCHIMMELFENNIG and SEDELMEIER- The Politics of EU ..., pp. 6-9.
} 
alargamento dos Estados-membros (o que leva um Estado-membro a apoiar ou a oporse à adesão de um candidato); (3) a política de alargamento da UE (sob que condições é que uma organização regional admite um novo membro); e (4) o impacto do alargamento (como e em que medida o novo Estado-membro é afectado pela adesão).

Para Lee Miles, por sua vez, a teoria do alargamento deve focar-se em três elementos principais: (1) conceptualizar o processo de adesão à UE, com recurso às condições, procedimentos e problemas das negociações; (2) examinar os processos de transição dos Estados-membros antigos e novos, assim como os dos candidatos; e (3) analisar o impacto dos alargamentos passados e futuros para a $\mathrm{UE}^{42}$. Visão semelhante tem Fernando Guirao quando salienta que qualquer pesquisa sobre o alargamento requer a procura de explicações para várias questões, tais como porque é que um Estado decide entregar parte da sua soberania; porque é que os Estados-membros e as instituições comunitárias aceitam que o alargamento se realize e sob que condições; de que modo é que os candidatos e os Estados-membros se preparam para as negociações ${ }^{43}$.

Concretamente, na perspectiva da teoria intergovernamental da integração europeia, os actores mais importantes em qualquer negociação de adesão serão os Estados-membros, tanto no respeitante à definição dos termos de adesão com os candidatos, como entre os próprios Estados-membros na adopção das posições comuns a apresentar ${ }^{44}$, sendo a sua importância ainda mais enaltecida se equacionarmos que o alargamento é decidido através de voto por unanimidade.

No entanto, o processo de alargamento extravasa a abordagem governamental, nomeadamente no que diz respeito ao papel da Comissão. Tanto os neofuncionalistas como as teorias institucionalistas defendem que as instituições supra-estaduais também desempenham um papel importante no processo de alargamento. A Comissão, através do Parecer, pode influenciar o Conselho quanto à abertura das negociações assim como quanto ao seu conteúdo e, no final, também elabora a sua opinião sobre o conteúdo do tratado. Além disso, ao efectuar uma primeira análise ao acervo comunitário com os candidatos e ao preparar propostas para as posições comuns a apresentar nas negociações ${ }^{45}$, amplia ainda mais a sua influência.

\footnotetext{
${ }^{42}$ MILES - Theoretical Considerations, p. 254.

${ }^{43}$ GUIRAO, Fernando - Solving the Paradoxes of Enlargement: The Next Research Challenge in our Field, p. 5.

${ }^{44}$ BAUN - A Wider Europe ..., p. 16.

${ }^{45}$ BAUN - A Wider Europe..., p. 17.
} 
Embora seja possível analisar o alargamento à luz das teorias da integração europeia existentes, é um facto que as teorias da integração e o alargamento têm caminhado em direcções opostas, dado que, primeiro, as teorias existentes dedicaram-se a explicar o que acontece dentro da UE em vez de estudar as relações entre a UE e países terceiros; e depois, mais recentemente, essas teorias têm-se tornado mais comedidas e menos ambiciosas, justamente numa altura em que o alargamento preenchia bastante a agenda da União ${ }^{46}$. De qualquer modo, não existe ainda nenhuma teoria que permita compreender em toda a sua abrangência a natureza e o impacto do alargamento.

Mesmo assim, há um movimento contínuo de interesse e de estudo sobre o alargamento, sendo que Geoffrey Pridham fala inclusive numa nova área de estudo dentro dos Estudos Europeus, os estudos sobre o alargamento, cujo aparecimento é suportado por: (1) a dimensão do alargamento de 2004; (2) a reunificação da Europa do Leste e do Oeste; (3) os diferentes tipos de Estados candidatos; (4) um processo de adesão mais elaborado; e (5) uma preocupação sem precedente acerca do impacto do alargamento na própria $\mathrm{UE}^{47}$. Como o próprio refere, "nos últimos anos o estudo do alargamento da União Europeia tem-se tornado uma área de investigação académica e um campo autónomo de estudo dentro dos Estudos Europeus", sendo que, para tal contribuíram dois fenómenos: o desenvolvimento crescente do estudo da europeização e o surgimento das primeiras abordagens teóricas acerca do alargamento, sobretudo fundamentadas em teorias das relações internacionais ${ }^{48}$, o que despertou um interesse crescente por esta área de estudo.

Após 2004, a UE manifesta sinais de padecer de "fadiga do alargamento"49, o que coloca dificuldades adicionais aos candidatos presentes e futuros. De facto, logo após esse alargamento a questão que se colocava era quem iria pagar essa "factura", não apenas em termos económicos mas também no que respeita à própria evolução do processo de integração europeu. Além disso, começava então também a instaurar-se uma crise de confiança entre os Estados-membros o que, aliado à criação da zona Euro e ao alargamento, "mostrou os limites do andamento da bicicleta da fábula"50. Em oposição a esta "fadiga do alargamento", não tem havido fadiga nos estudos sobre o

\footnotetext{
${ }^{46}$ MILES - Theoretical Considerations ..., p. 264.

${ }^{47}$ PRIDHAM - The Arrival of Enlargement ..., pp. 1-2.

${ }^{48}$ PRIDHAM - The Arrival of Enlargement ..., p. 1, pp. 14-19.

49 SCHIMMELFENNIG - EU Political Accession ..., p. 919.

${ }^{50}$ FERREIRA, José Medeiros - Bons alunos de maus mestres, p. 92.
} 
alargamento, estando esta área inscrita na agenda da integração europeia como um assunto importante, não periférico e passageiro e que adquiriu um sentido de continuidade ${ }^{51}$.

\section{Notas finais}

O alargamento sempre fez parte da missão história da CEE/UE de unir a Europa e tem contribuído para a manutenção da paz e para a prosperidade do continente europeu. Aliás, podemos mesmo considerar o alargamento como a mais poderosa política que a UE tem para manter a paz e impulsionar a prosperidade, além de serem reconhecidos igualmente os benefícios políticos da instauração da democracia, dos direitos humanos e do Estado de direito.

Menos de quatro anos após a criação da CEE, já havia candidatos à adesão. Em cinquenta anos de história, a questão do alargamento colocou-se por várias vezes, culminando até à data em sete rondas de alargamento, mas continuando na "ordem do dia" comunitária, embora sem a força de outrora. De resto, os próprios debates da academia sobre as perspectivas e os perigos do alargamento dividem-se por campos extremos, convergindo apenas no que diz respeito ao facto do alargamento ser indissociável da discussão sobre o próprio futuro da Europa.

Tal como demonstrado, de uma ausência clara de condições concretas para o alargamento, os requisitos formais para a adesão foram sendo aperfeiçoados ao longo das sucessivas rondas de alargamento, sendo que o próprio processo de negociações reveste-se actualmente de uma grande complexidade, ao passo que os candidatos se veem perante a exigência de grandes reformas estruturais internas, e a própria UE perante a necessidade de adaptar o seu sistema institucional, tudo num processo natural de adaptação para os novos Estados-membros e de readaptação para os Estadosmembros mais antigos e para as instituições europeias ${ }^{52}$.

Embora a UE continue comprometida com o alargamento, os Estados-membros estão a utilizar outras estratégias para controlar o processo de adesão, o que faz com que todo o processo se torne ainda mais imprevisível. Não será de facto de esperar nos próximos anos um novo alargamento. De resto, o próprio candidato do Partido Popular

\footnotetext{
${ }^{51}$ PRIDHAM - The Arrival of Enlargement ..., p. 19.

${ }^{52}$ A questão do impacto que o alargamento acarreta para todos os intervenientes no processo não foi, deliberadamente, abordada neste artigo, primeiro por não ser esse o objectivo do artigo e depois por ser uma questão infindável, passível de múltiplos artigos e análises.
} 
Europeu à presidência da Comissão Europeia, Jean Claude Junker, afirmou recentemente defender o princípio de uma pausa no alargamento, referindo que: "aconselho cautelas e razoabilidade quando falamos do alargamento da União Europeia. Eu era um entusiasta em 2004 à medida que a União se expandia para a Europa central e oriental. Mas agora acredito que precisamos de uma pausa no alargamento. Por vezes, devemos pensar na Europa antes de agir" ${ }^{, 53}$.

Concluindo, apesar das múltiplas fragilidades da política do alargamento, com regras ainda não claramente bem definidas, com procedimentos nem sempre claros e com o preço que se paga por cada alargamento, tanto para a União como um todo, como para os Estados-membros individualmente, a UE continua a ser considerada como "o melhor clube da Europa" ${ }^{, 54}$ para se aderir.

\section{Bibliografia}

ATHANASSIOU, Phoebus - Withdrawal and Expulsion from the EU and EMU: Some Reflections [Em linha]. ECB Legal Working Paper No. 10, 2009. [consultado a 07/03/2014].

Disponível em WWW: http://papers.ssrn.com/sol3/papers.cfm?abstract_id=1517760.

AVERY, Graham and CAMERON, Fraser - The Enlargement of the European Union. Sheffield: Sheffield Academic Press, 1998. ISBN 1850758530.

BAUN, Michael J. - A Wider Europe: The Process and Politics of European Union Enlargement. Lanham: Rowman \& Littlefield Pub Inc., 2000. ISBN 0847690377.

BERGLUND, Sara - Prison or voluntary cooperation? The possibility of withdrawal from the European Union. Scandinavian Political Science. Oslo: Nordic Political Science Association. ISSN 0080-6757. Vol. 29, No. 2 (2006), pp. 147-167.

53 Europeias: Juncker pede cautela no alargamento da UE. [Em linha]. Consultado a 17/03/2014. Disponível em WWW: http://pt.euronews.com/2014/04/05/europeias-juncker-pede-cautela-noalargamento-da-ue/.

${ }^{54}$ PRESTON - Enlargement and Integration ..., p. 3. 
CAPORASO, James A. - Regional Integration Theory: Understanding Our Past and Antecipating Our Future. In SANDHOLTZ, Wayne and SWEET, Alec Stone (eds.) European Integration and Supranational Governance. Oxford: Oxford University Press, 1998, pp. 334-351, ISBN 0198294573.

COMISSÃO - Boletim das Comunidades Europeias. N. ${ }^{\circ}$ 2. Bruxelas: Comissão das Comunidades Europeia, 1985.

COMISSÃO EUROPEIA - 10 Sucessos que Partilhamos na União Europeia. Lisboa: Comissão Europeia - Representação em Portugal, 2010.

ELVERT, Jürgen - A Fool's Game or a Comedy of Errors?: EU Enlargements in Comparative Perspective. In KAISER, Wolfram and ELVERT, Jürgen (ed.) - European Union Enlargement - A Comparative History. London: Routledge, 2004, pp. 189-208, ISBN 1134323859.

EUROPEAN COMMISSION, Eurobarometer No. 42, Spring 1995, Brussels.

EUROPEAN COMMISSION, Eurobarometer 61, Spring 2004, National Report Portugal, Lisboa.

FERREIRA, José Medeiros - Bons alunos de maus mestres. Relações Internacionais. Lisboa: IPRI. ISSN 1645-9199. N. 7 (2005), pp. 89-96.

GUIRAO, Fernando - Solving the Paradoxes of Enlargement: The Next Research Challenge in our Field. Journal of European Integration History. Essen: Groupe de Liason des Professeurs d'Histoire auprès de la Commission Européenne. ISSN 0947951. Volume 11, Number 2 (2005), pp. 5-9.

HILLION, Christophe - The Creeping Nationalisation of the EU Enlargement Policy. Stockholm: Swedish Institute for European Policy Studies, Report No. 6, 2010. 
KAISER, Wolfram - What Alternative is Open to Us?': Britain. In KAISER, Wolfram and ELVERT, Jürgen (eds.) - European Union Enlargement - A Comparative History. London: Routledge, 2004, pp. 9-30. ISBN 1134323859.

LAURSEN, Johnny - A Kingdom Divided: Denmark. In KAISER, Wolfram and ELVERT, Jürgen (eds.) - European Union Enlargement - A Comparative History. London: Routledge, 2004, pp. 31-52. ISBN 1134323859.

LECHNER, Susanne and OHR, Renate - The right of withdrawal in the treaty of Lisbon: a game theoretic reflection on different decision processes in the EU. European Journal of Law and Economics. Switzerland: Springer. ISSN: 0929-1261. No. 32 (2011), pp. 357-375.

MILES, Lee - Theoretical Considerations. In NUGENT, Neill (ed.) - European Union Enlargement. Houndmills: Palgrave Macmillan, 2004, pp. 253-265. ISBN 1403913528.

MORAVCSIK, Andrew and VACHUDOVA, Milada Anna - National Interests, State Power, and EU Enlargement. East European Politics and Society. USA: Sage. ISSN 0888-3254. No. 17, 2003, pp. 42-57.

NUGENT, Neill - Distinctive and Recurring Features of Enlargement Rounds. In NUGENT, Neill (ed.) - European Union Enlargement. Houndmills: Palgrave Macmillan, 2004, pp. 56-69. ISBN 1403913528.

PARSONS, Craig - A Certain Idea of Europe, Ithaca: Cornell University Press, 2003. ISBN 0801472962.

PRESTON, Christopher - Enlargement and Integration in the European Union. London: UACES, 1997. ISBN 0415120012.

PRESTON, Christopher - Obstacles to EU Enlargement: The Classical Community Method and the Prospects for a Wider Europe. Journal of Common Market Studies. London: University Association for Contemporary European Studies, ISSN 1468-5965. Volume 33, Issue 3 (1995), pp. 451-463. 
PRIDHAM, Geoffrey - The Arrival of Enlargement Studies: Patterns and Problems. CRCEES Working Paper Series, Glasgow: University of Glasgow, 2008.

RUANO, Lorena - Origins and Implications of the European Union's Enlargement Negotiations Procedure. RSC No. 2002/62, EUI Working Papers, 2000.

SCHIMMELFENNIG, Frank - EU Political Accession Conditionality after the 2004 Enlargement: Consistency and Effectiveness. Journal of European Public Policy. London: Taylor \& Francis. ISSN 1350-1763. Volume 15, Issue 6 (2008), pp. 918-937.

SCHIMMELFENNIG, Frank and SEDELMEIER, Ulrich - The Politics of EU Enlargement: Theoretical and Comparative Perspectives. In SCHIMMELFENNIG, Frank and SEDELMEIER, Ulrich (eds.) - The Politics of European Union Enlargement: Theoretical Approaches. London: Routledge, 2009, pp. 3-29. ISBN 0203008723.

SCHNEIDER, Christina J. - Conflict, Negotiation and European Union Enlargement. Cambridge: Cambridge University Press, 2009. ISBN 0521514819.

WALLACE, Helen - Enlarging the European Union: Reflections on the Challenge of Analysis. In SCHIMMELFENNIG, Frank and SEDELMEIER, Ulrich (eds.) - The Politics of European Union Enlargement: Theoretical Approaches. London: Routledge, 2009, pp. 287-294. ISBN 0203008723. 